\title{
Are standardized caries risk assessment models effective in assessing actual caries status and future caries increment? A systematic review
}

Maria Grazia Cagetti ${ }^{1,2^{*}}$ D, Giuliana Bontà ${ }^{1}$, Fabio Cocco $^{2,3}$, Peter Lingstrom ${ }^{4}$, Laura Strohmenger ${ }^{1,2}$ and Guglielmo Campus ${ }^{2,3}$

\begin{abstract}
Background: Assessing caries risk is an essential element in the planning of preventive and therapeutic strategies. Different caries risk assessment (CRA) models have been proposed for the identification of individuals running a risk of future caries. This systematic review was designed to evaluate whether standardized caries risk assessment (CRA) models are able to evaluate the risk according to the actual caries status and/or the future caries increment.

Methods: Randomized clinical trials, cross-sectional studies, cohort studies, comparative studies, validation studies and evaluation studies, reporting caries risk assessment using standardized models (Cariogram, CAMBRA, PreViser, NUS-CRA and (AT) in patients of any age related to caries data recorded by DMFT/S or ICDAS indices, were included. PubMed, Scopus and Embase were searched from 2000 to 2016. A search string was developed. All the papers meeting the inclusion criteria were subjected to a quality assessment.

Results: One thousand three-undred ninety-two papers were identified and 32 were included. In all but one, the Cariogram was used both as sole model or in conjunction with other models. All the papers on children $(n=16)$ and adults $(n=12)$ found a statistically significant association between the risk levels and the actual caries status and/or the future caries increment. Nineteen papers, all using the Cariogram except one, were classified as being of good quality. Three of four papers comprising children and adults found a positive association. For seven of the included papers, Cariogram sensibility and specificity were calculated; sensibility ranged from low (41.0) to fairly low (75.0), while specificity was higher, ranging from 65.8 to 88.0 . Wide $95 \%$ confidence intervals for both parameters were found, indicating that the reliability of the model differed in different caries risk levels.

Conclusions: The scientific evidence relating to standardized CRA models is still limited; even if Cariogram was tested in children and adults in few studies of good quality, no sufficient evidence is available to affirm the method is effective in caries assessment and prediction. New options of diagnosis, prognosis and therapy are now available to dentists but the validity of standardized CRA models still remains limited.
\end{abstract}

Keywords: Dental caries, Dental caries susceptibility, Dental health surveys, Risk assessment, Review

\footnotetext{
* Correspondence: maria.cagetti@unimi.it

'Department of Biomedical, Surgical and Dental Sciences, University of Milan,

Via Beldiletto 1, 20142 Milan, Italy

WHO Collaboration Centre for Epidemiology and Community Dentistry, Via

Beldiletto 1, 20142 Milan, Italy

Full list of author information is available at the end of the article
}

(c) The Author(s). 2018 Open Access This article is distributed under the terms of the Creative Commons Attribution 4.0 International License (http://creativecommons.org/licenses/by/4.0/), which permits unrestricted use, distribution, and reproduction in any medium, provided you give appropriate credit to the original author(s) and the source, provide a link to the Creative Commons license, and indicate if changes were made. The Creative Commons Public Domain Dedication waiver (http://creativecommons.org/publicdomain/zero/1.0/) applies to the data made available in this article, unless otherwise stated. 


\section{Background}

Different caries risk assessment (CRA) models have been proposed for the identification of individuals running a risk of future caries [1-7].

Caries is a multifactorial disease resulting from a series of events occurring in a chain that lasts for years where clinical, microbiological, behavioral and social factors are involved in the process. In view of its multifactorial nature, a multivariate approach is necessary [8]. The scientific basis for caries risk assessment, prevention and treatment on an individual patient basis requires incessant development, specification and continuing validation [9]. Scientific evidence proving CRA methods' validity is limited [3]. Past caries experience is regarded as the single most powerful caries predictor in all age groups $[4-7,10]$. Different measures of past caries experience are often included in analytical models of multi-risk studies. Nevertheless, there are consequences of including past caries experience measures for both prediction and multi-risk models since this parameter will hide the effects of weaker indicators of high risk individuals or of other caries risk-factors [11].
Caries risk assessment still has great potential to enhance patient care as it is the corner stone of a minimal invasive care plan, allowing the determination of the appropriate non-invasive as well as invasive interventions and recall strategies [12], but still today, a great need to standardize study design, outcome measures and reporting of data in studies on CRA is required [13].

Standardized models including different combinations of risk and protective factors (Table 1) have been developed from the 2000s onwards to predict caries; they can be summarized in two main categories, those using an algorithm with a software program and those using standardized questionnaires (self-submitted and/or through an interview). Moreover, CRA methods could be used as an effective health-education tool to change the attitudes and behaviors of patients/parents/caregivers towards good oral hygiene and dietary habits maintenance [14].

Nowadays, no systematic reviews are available on the performances of standardized models. Recent reviews have attempted to assess the validity of different caries risk assessment models/factors [3, 10, 13]. Two reviews combined single clinical parameters and standardized

Table 1 Different factors included in each standardized Caries Risk Mode

\begin{tabular}{|c|c|c|c|c|c|c|}
\hline \multirow[b]{2}{*}{ Factors } & \multicolumn{3}{|c|}{ Software programs } & \multicolumn{3}{|c|}{ American Dental Association models } \\
\hline & $\begin{array}{l}\text { NUS-CRA } \\
11 \text { factors }\end{array}$ & $\begin{array}{l}\text { Cariogram } \\
9 \text { factors }\end{array}$ & $\begin{array}{l}\text { PreViser } \\
11 \text { factors }\end{array}$ & $\begin{array}{l}\mathrm{ADA} \\
11 \text { factors }\end{array}$ & $\begin{array}{l}\text { CAMBRA } \\
14 \text { factors }\end{array}$ & $\begin{array}{l}\text { CAT } \\
12 \text { factors }\end{array}$ \\
\hline \multicolumn{7}{|l|}{ Socio-demographic } \\
\hline Age & $x$ & & $x$ & & & \\
\hline Ethnicity & $x$ & & & & & \\
\hline Family socioeconomic status & $x$ & & & $x$ & $x$ & $x$ \\
\hline \multicolumn{7}{|l|}{ Behavioural } \\
\hline Infant feeding history & $x$ & & & & $x$ & \\
\hline Diet & $x$ & $x$ & $x$ & $x$ & $x$ & $x$ \\
\hline Fluoride & $x$ & $x$ & $x$ & $x$ & $x$ & $x$ \\
\hline Dental attendance & & & $x$ & $x$ & $x$ & $x$ \\
\hline \multicolumn{7}{|l|}{ Clinical } \\
\hline Oral hygiene & $x$ & $x$ & $x$ & $x$ & $x$ & $x$ \\
\hline Past caries & $x$ & $x$ & $x$ & $x$ & $x$ & $x$ \\
\hline White spot lesions & & & & $x$ & $x$ & $x$ \\
\hline Enamel defects & & & & & & $x$ \\
\hline Dental appliance & & & $x$ & $x$ & $x$ & $x$ \\
\hline Systemic health & $x$ & $x$ & $x$ & $x$ & $x$ & $x$ \\
\hline Medication & & & & $x$ & $x$ & \\
\hline \multicolumn{7}{|l|}{ Salivary and microbiological } \\
\hline Saliva flow rate & & $x$ & $x$ & $x$ & $x$ & $x$ \\
\hline Saliva buffering capacity & & $x$ & & & & \\
\hline Mutans streptococci & $x$ & $x$ & $x$ & & $x$ & $x$ \\
\hline Lactobacilli & $x$ & $x$ & $x$ & & $x$ & \\
\hline
\end{tabular}

NusCra National University of Singapore Caries Risk Assessment, CAMBRA Caries Management By Risk Assessment, ADA caries risk assessment by American Dental Association, CAT America Academy of Pediatric Dentistry's Caries Assessment Tool 
caries risk assessment models [3, 13]. The only externally validated model was the Cariogram [13]; the accuracy of the standardized model was found to be limited in pre-school children, based on two papers $[15,16]$. The search literature contained a time frame from 1966 to 2006 with a refresh in 2011, so the most recent papers were not included in the review. Otherwise, Tellez et al. [3] aimed to appraise the evidence in caries prediction of two standardized CRA models, Cariogram, and Caries Management by Risk Assessment (CAMBRA), and two guidelines of the American Dental Association (ADA) and the American Academy of Pediatric Dentistry (AAPD), taking into account six longitudinal studies. In this review, the literature search was also stopped in 2011. Senneby et al. [13] evaluated the association between previous caries experience, microbiological tests, buffering capacity, salivary flow rate, oral hygiene, dietary habits, socio-demographic variables and the future caries lesion development. The evidence was considered of low quality and was lacking in regards to the studied methods. The literature search was stopped in January 2015.

Starting from these premises, this review aimed to evaluate the current literature on standardized CRA models, verifying whether the risk level measured using different tools is associated with the actual caries status and/or the future caries increment.

\section{Methods}

This systematic review was conducted and reported following the Preferred Reporting Items for Systematic Reviews and Meta-analyses (PRISMA Statement) checklist.

\section{Protocol and registration}

The review method and planning were registered at Prospero (PROSPERO 2016:CRD42016038590).

\section{Eligibility criteria}

Randomized controlled trial (RCT), cross-sectional studies, cohort studies, comparative studies, validation studies and evaluation studies, reporting CRA using standardized models in patients of any age related to caries data recorded by Decayed, Missing, Filled Tooth/ Surface (DMFT/S) or the International Caries Detection and Assessment System (ICDAS) indices were included. Only papers in English published from the 1st of January 2000 to the 31st of December 2017 were collected. This time frame was chosen since no standardized CRA tools were studied before the year 2000 as emerged from a first evaluation made by two authors (GC and MGC).

\section{Information sources and search strategy}

Three different electronic databases were searched: PubMed, Scopus ${ }^{\circ}$ and Embase ${ }^{\bullet}$. Two search strategies were used; the first included a combination of $\mathrm{MeSH}$ terms and key words: caries risk assessment, caries risk assessment models, caries risk assessment tools, caries risk epidemiology, caries risk profile, Cariogram, CAMBRA, PreViser, NUS-CRA, ADA caries risk assessment, CAT caries risk assessment, AAPD caries risk assessment and dental caries susceptibility. The second strategy included the search string "((dentistry) OR (dental caries) OR (caries)) AND ((caries risk assessment) OR (Cariogram) OR (CAMBRA) OR (AAPD) OR (CAT) OR (ADA) OR (nuscra) OR (NUS-CRA) OR (PreViser)) AND ((cross-sectional studies) OR (cohort analysis risk) OR (cohort studies) OR (clinical trial) OR (clinical study) OR (controlled clinical trial) OR (observational study))".

\section{Study selection}

Repeated papers were deleted after comparing the results from the two different search strategies using the three databases. Two authors (GB and MGC) independently examined all the abstracts of the papers (see Additional file 1 for the whole list). All the papers meeting the inclusion criteria were obtained in the full-text format. The two authors independently assessed the papers to establish whether each paper should or should not be included in the systematic review (see Additional file 2 for the list of the papers excluded at this stage).

\section{Data collection}

Data collection was carried out using an ad hoc designed data extraction form without masking journal title or authors. Data were extracted by two authors (MGC, GC) independently. For each paper the following data were searched and recorded when available: a) the year of publication and duration of the study; b) details of the participants including sample size at baseline, age and country of origin; c) caries data including actual caries status, caries experience and caries increment measured through DMFT/S or $\mathrm{dmft} / \mathrm{s}$ or ICDAS; d) Caries risk assessment including standardized model used and categorization of the risk levels; e) sensibility and specificity of the CRA model.

Row data were requested to authors of longitudinal studies to perform data synthesis and analysis.

\section{Assessment of risk of bias and risk of bias across studies}

The risk of bias assessment was conducted by two authors (GC and MGC). The methodological quality of the included studies was scored according to the customized quality assessment tool developed by the National Heart, Lung, and Blood Institute and Research Triangle Institute International for Observational Cohort and Cross-Sectional Studies since, as reported in the result section no RCTs were obtain after studies' selection [17] (see Additional file 3 for quality assessment of 
included studies). Disagreements between authors were resolved by discussion. Where this was not possible, other authors were consulted (PL).

\section{Synthesis of the results}

To facilitate a comparison of the results from different studies, the caries values were organized in two-by-two tables. Based on these tables, sensitivity and specificity were calculated, along with the corresponding $95 \%$ confidence intervals.

\section{Results}

This review provides a concise description of the findings of the included papers, structured around the association between the standardized CRA models, performed on children and/or adults, and the actual or the predicted caries status.

The search identified 3326 papers; after removing duplicates, 1934 papers were selected and, after reviewing titles, abstracts and texts, 32 papers were finally included: 16 on children, 12 on adults and 4 on both, 3 of which considered children and adults as a single sample and one as two different samples (Fig. 1). In order to record caries status (experience/prevalence/incidence), 9 papers used DMFT index or sub-components, 13 papers used DMFS index or sub-components and only 1 used the ICDAS. Four papers focused on primary teeth, 24 on permanent teeth and 4 on both dentitions. The majority of papers $(n=31)$ estimated the caries risk using the Cariogram as a single model or in comparison with other models. No RCTs were included in the systematic review. All the considered longitudinal papers were comparative studies or validation studies or retrospective cohort studies or, finally, evaluation studies. All the included papers along with the quality assessment grade are reported in Table 2. Nineteen papers were classified as being of good quality, 9 papers of fair quality and only 4 of low quality.

\section{Association between caries risk level and actual caries status in children}

Two papers $[18,19]$ evaluated the association between caries prevalence (DMFS) and Cariogram 9 factors (hereinafter named Full Cariogram) in orthodontic patients. The low caries group at baseline displayed a statistically significant difference regarding caries increment and Cariogram level. Neither DMFT nor the number of caries lesions differed significantly in the Cariogram's risk categories (7 factors) in a sample of Chilean subjects [20]. Children with a cleft lip and/or palate and non-cleft controls classified in the Cariogram high-risk category had a higher caries experience [21]. A significant linear regression between mean $\mathrm{dmft}$ and caries risk categories assessed according to a form based on the Cariogram was found in children from low-income families $(p<0.01)$ [22]. A statistically significant association between caries experience and Cariogram categories was found $(p<0.01)$ in Indian children [23]. Caries experience and the presence of white spot lesions were statistically significantly associated with Cariogram categories in Greek pre-school

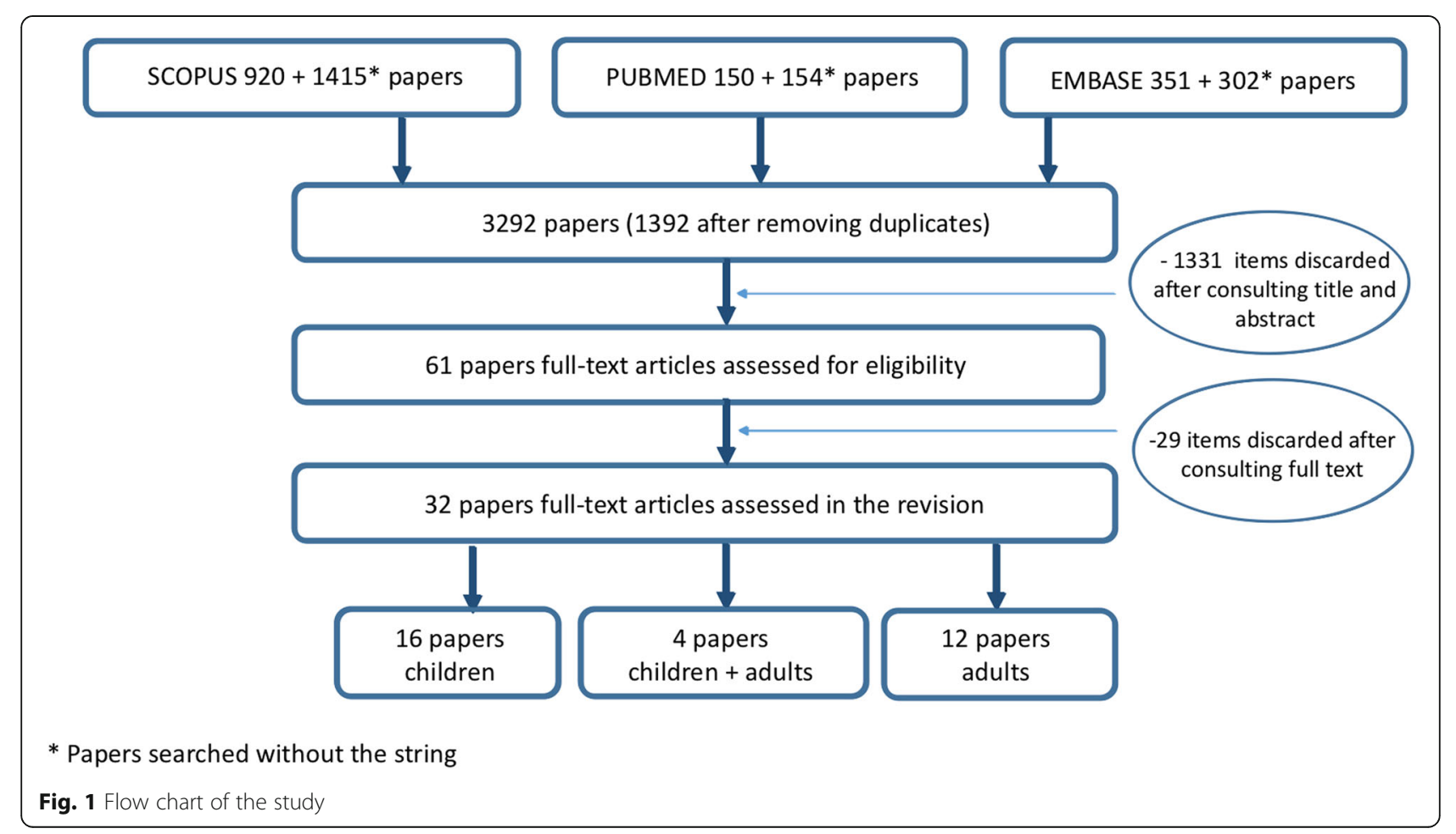


Table 2 Papers included. Association between standardized CRA and actual caries status and/or caries prediction

\begin{tabular}{|c|c|c|c|c|c|c|}
\hline Authors (year) & Outcome & Subjects & Indices & Caries risk model & Statistical significance & Quality assessment \\
\hline \multicolumn{7}{|l|}{ Children/Adolescents } \\
\hline $\mathrm{Gao}^{\mathrm{b}},(2015)[8]$ & $\mathrm{Cl}$ & 544 & $\mathrm{dmft}$ & $\begin{array}{l}\text { Full Cariogram, CAT, CAMBRA, NUS- } \\
\text { CRA }\end{array}$ & + & Good \\
\hline Sundel, (2015) [21] & ACS & 133 & dmfs/DMFS & Full Cariogram & + & Good \\
\hline Cabral, (2014) [22] & ACS & 150 & $\mathrm{dmft} / \mathrm{DMFT}$ & Form based on Cariogram 7 factors & ++ & Poor \\
\hline Kemparaj, (2014) [37] & $\mathrm{Cl}$ & 200 & DMFT/S & Full Cariogram & + & Poor \\
\hline $\mathrm{Gao}^{\mathrm{b}},(2013)[36]$ & $\mathrm{Cl}$ & 544 & $\mathrm{dmft}$ & $\begin{array}{l}\text { Full Cariogram, CAT, CAMBRA, NUS- } \\
\text { CRA }\end{array}$ & + & Good \\
\hline Zukanovich, (2013) [41] & $\mathrm{Cl}$ & 109 & DMFS/DMFT & Full Cariogram, PreViser, CAT & + & Fair \\
\hline Campus, (2012) [35] & $\mathrm{Cl}$ & 957 & DFS & Cariogram 7 factors & + & Good \\
\hline Hebbal, (2012) [23] & ACS & 100 & DMFT & Full Cariogram & ++ & Poor \\
\hline Kavvadia, (2012) [24] & ACS & 814 & $\mathrm{dmft}$ & Full Cariogram & + & Fair \\
\hline Gao, (2010) [16] & $\mathrm{Cl}$ & 1576 & $\mathrm{dmft}$ & Full Cariogram & e & Good \\
\hline Petersson $^{c},(2010 b)[39]$ & $\mathrm{Cl}$ & 392 & DMFS & Full Cariogram, Cariogram 6 factors & + & Good \\
\hline Petersson, (2010a) [40] & $\mathrm{Cl}$ & 392 & DMFS & Full Cariogram & + & Good \\
\hline Campus, (2009) [25] & ACS & 957 & $\mathrm{dmfs} / \mathrm{DMFS}$ & Cariogram 7 factors & ++ & Good \\
\hline Holgerson, (2009) [15] & $\mathrm{Cl}$ & 125 & dmfs/DMFS & Full Cariogram & + & Fair \\
\hline Twetman, (2005) [33] & $\mathrm{Cl}$ & 64 & DFS & Full Cariogram & ++ & Good \\
\hline Petersson ${ }^{a, b},(2004)[34]$ & $\mathrm{Cl}$ & 446 & DFS & Full Cariogram & ++ & Good \\
\hline Petersson $^{b}$, (2002) [32] & $\mathrm{Cl}$ & 446 & DMFT/S & Full Cariogram & + & Good \\
\hline \multicolumn{7}{|l|}{ Adults } \\
\hline Petersson, (2015) [44] & $\mathrm{Cl}$ & 1295 & DFT/DFTS & Full Cariogram & ++ & Good \\
\hline Carta, (2015) [31] & ACS & 480 & ICDAS & Full Cariogram & ++ & Good \\
\hline Chaffee, (2015) [45] & $\mathrm{Cl}$ & 4468 & DFS & CAMBRA & + & Good \\
\hline Chang (2014) [30] & $\mathrm{Cl}$ & 110 & DMFT/S & Cariogram 7 factors & + & Good \\
\hline Chang and Kim, (2014) [42] & ACS & 102 & DMFT & Full Cariogram & + & Good \\
\hline Lee, (2013) [29] & ACS & 80 & DMFT & Full Cariogram, Cariogram $7 / 8$ factors & + & Fair \\
\hline Petersson, (2013) [7] & ACS & 1295 & $\mathrm{DFT} / \mathrm{S}$ & Cariogram 8 factors & ++ & Good \\
\hline Celik, (2012) [43] & $\mathrm{Cl}$ & 100 & DMFT/S & Full Cariogram & + & Fair \\
\hline Peker, (2012) [27] & ACS & 90 & DMFT/S & Full Cariogram & + & Fair \\
\hline Sonbul, (2008) [28] & ACS & 175 & DMFS & Full Cariogram & + & Good \\
\hline Ruiz Miravet, (2007) [26] & ACS & 48 & DMFT/S & Full Cariogram & ++ & Poor \\
\hline Petersson" ${ }^{\mathrm{a}, \mathrm{d}},(2004)$ [34] & $\mathrm{Cl}$ & 208 & DFS & Full Cariogram & ++ & Fair \\
\hline Petersson $^{d}$, (2003) [1] & $\mathrm{Cl}$ & 208 & DMFS /DFS/DFRS & Full Cariogram & ++ & Good \\
\hline \multicolumn{7}{|l|}{ Both Children/Adults } \\
\hline Giacaman, (2013) [20] & ACS & 180 & DMFT & Cariogram 7 factors & - & Poor \\
\hline Almosa, (2012) [18] & ACS & 89 & DMFS & Full Cariogram & ++ & Fair \\
\hline Al Mulla, (2009) [19] & ACS & 100 & DFS & Full Cariogram & ++ & Fair \\
\hline
\end{tabular}

ACS actual caries status, $C I$ Caries Increment. Subjects: number of subjects at baseline

Statistical significance: $-=p>0.05+=p<0.05 ;++=p \leq 0.01$

aPetersson, (2004) reported in both children and adults and describes data in two different samples

${ }^{\mathrm{b}} \mathrm{GaO},(2013)$ and (2015), and Petersson, (2002) and (2004) respectively reported data for the same sample of children

'Petersson, (2010a) and (2010b) reported data for the same sample of children

dPetersson, (2003) and (2004) reported data for the same sample of elderly people

${ }^{\mathrm{e}}$ Data not obtainable from the paper 
children $(p<0.01)$ [24]. A significant linear trend between the five Cariogram categories and dmfs/DMFS scores was observed $(p<0.01)$ in Italian children [25].

\section{Association between caries risk level and actual caries status in adults}

Several papers focused on young adults and all of them reported an association between Cariogram categories and caries prevalence/experience/severity [7, 26, 27]. In Saudi Arabia [28], the mean caries prevalence in the high-risk group differed significantly from that recorded in the low-risk group $(p<0.05)$. A caries profile obtained from the Cariogram, including 7 and 8 factors, was compared to the Full Cariogram and correlated to caries experience: all models measured statistically significant associated risk levels to the caries experience [29]. The chance of avoiding caries was statistically significantly associated $(p<0.01)$ to the caries experience in a group of Korean adults [30]. Caries at ICDAS levels 5-6 and the presence of more than five missing teeth were statistically significant associated to the Cariogram scores $(\mathrm{OR}=2.36,95 \% \mathrm{CI}=1.83-3.03$ and $\mathrm{OR}=1.43,95 \% \mathrm{CI}=$ $1.13-1.82$ respectively) in Italian adults [31].

\section{Association between caries risk level and caries increment in children and adults}

A total of 17 longitudinal papers investigated the validity of standardized CRA models to predict new caries lesions (Table 3). Twelve papers regarding children were included $[15,16,32-41]$, nine of which used the Cariogram model and three compared different CRA models, including the Cariogram [36, 38, 41]. Six papers regarding adults were included, five of which used the Cariogram [1,34, 42-44] and one the CAMBRA model [45].

In a two-year prospective study [32] subjects in the highest risk group developed a mean of about 10 times more caries lesions (DMFS) than the lowest risk group. The same authors compared [34] data from the previous study with those recorded in a group of adults/elderly people, showing a higher mean of caries increment per year for high-risk groups. The caries increment in children affected by Type 1 diabetes mellitus ( $\triangle$ DMFS) was about eight times higher in the Cariogram highest risk category [33]. After five years from baseline, children classified at high risk (Full Cariogram) developed about four times more caries lesions [15] (study not included in Table 3). Five times more caries lesions were found in schoolchildren assessed by the Full Cariogram as running the highest risk compared with those with the lowest risk [40]. On the same sample, two different Cariogram models with and without saliva factors were tested. Both models revealed a statistically significant relationship with caries development $(p<0.05)$ at the two-year follow-up [39]. A prospective study (not included in Table 3) was conducted on preschool children with different risk assessment models, including the Full Cariogram [16]. One year after baseline the model showed a sensitivity/specificity lower values than the biopsychosocial models proposed by the authors. In Italian schoolchildren, the caries risk was assessed (7-factor Cariogram) and 2 years later the children classified as high risk developed caries lesions about as twice as much as those developed by children classified as low risk [35]. Full Cariogram, Previser and the Caries-risk Assessment Tool (CAT) were compared in children [41]. At the follow-up examination (3 years), only the Cariogram model successfully predicted new caries lesions. Full Cariogram, NUS-CRA, CAT and CAMBRA were assessed on preschool children [36]. After 1 year, using CAT and CAMBRA, the majority of children were considered to be at high risk, while, using the Full Cariogram and the National University of Singapore Caries Risk Assessment (NUS-CRA), almost $2 / 3$ of the children were defined as very low or low risk. The CRA was evaluated in a sample of 12-year-old children using the Full Cariogram and dividing them into five groups of risk [37]. Two years later, children classified as very high risk at baseline developed about thirty times more caries lesions compared to children classified as very low risk. The same sample of three-year-old children from a previous study [36] was re-evaluated 18 months from baseline $(n=462)$ using the same risk assessment model; a gradient in caries increment from lower to higher risk groups was found using all programs [38].

Full Cariogram was evaluated in elderly people and, after 5 years, subjects with the highest risk profile had about three times more caries lesions compared to the lowest risk group [1]. Full Cariogram was assessed in two samples of young adults [43, 44]; after 2 years, subjects classified at very high risk at baseline developed caries lesions about as twice as much as those classified at very low risk; at the 3 year follow-up of the second sample [44], subjects with the highest risk profile had about seven times more caries lesions compared to those in the lowest risk group. The CAMBRA model was used to split a sample of young adults into four risk groups [45]; caries increment was more than three times higher in subjects classified as high risk than those classified at low risk.

Few of the included papers report data allowing the authors to calculate sensibility and specificity of the CRA models $[15,16,32,33,35,36,44]$. In Table 4 the available data for the Cariogram model are displayed. Sensibility values ranged from low (41.0) [32] to fairly low (52.0) [35], while specificity values were quite high, ranging from 71.0 [33] to 88.0 [15]. Moreover, wide Confidences Intervals are reported for both parameters, indicating that the reliability of the model differs in the different caries risk levels. 
Table 3 Association between caries increment and caries risk model categories in longitudinal papers

\begin{tabular}{|c|c|c|c|c|c|c|c|c|c|}
\hline \multirow[t]{2}{*}{ Authors (year) } & \multirow[t]{2}{*}{ Age } & \multirow[t]{2}{*}{ Study time (years) } & \multirow[t]{2}{*}{ Subjects } & \multirow{2}{*}{$\begin{array}{l}\text { Caries increments } \\
\text { Cariogram }\end{array}$} & \multicolumn{5}{|c|}{ Range Mean (Standard Deviation) } \\
\hline & & & & & $0-20$ & $21-40$ & $41-60$ & $61-80$ & $81-100$ \\
\hline Gao (2013) [36] & C & 1 & 485 & $\mathrm{dmft}$ & $2.67(2.96)$ & $2.02(1.71)$ & $1.56(1.63)$ & $0.77(1.21)$ & $0.34(0.88)$ \\
\hline \multirow[t]{2}{*}{ Kemparaj (2014) [37] } & C & 2 & 200 & DMFT & $0.54(1.2)$ & $0.43(1.32)$ & $0.39(1.04)$ & $0.34(0.80)$ & $0.06(0.09)$ \\
\hline & & & & DMFS & $0.79(1.73)$ & $0.73(1.55)$ & $0.48(1.72)$ & $0.39(1.20)$ & $0.09(1.12)$ \\
\hline \multirow[t]{2}{*}{ Celik (2012) [43] } & A & 2 & 100 & DMFT & $1.23(0.86)$ & $0.65(0.81)$ & $0.39(1.02)$ & $0.08(0.28)$ & $0(0)$ \\
\hline & & & & DMFS & $1.23(0.86)$ & $0.9(0.97)$ & $0.48(1.6)$ & $0.08(0.28)$ & $0(0)$ \\
\hline \multirow[t]{2}{*}{ Petersson (2002) [32] } & C & 2 & 392 & DMFT & $1.67(1.44)$ & $1.46(2.20)$ & $1.07(1.36)$ & $0.42(0.90)$ & $0.23(0.61)$ \\
\hline & & & & DMFS & $2.58(1.83)$ & $2.62(4.11)$ & $1.47(1.81)$ & $0.53(1.24)$ & $0.27(0.70)$ \\
\hline Petersson (2015) [44] & A & 3 & 982 & DFT & $1.00(1.40)$ & $0.84(0.95)$ & $0.82(1.18)$ & $0.53(1.07)$ & $0.24(0.58)$ \\
\hline \multirow[t]{2}{*}{ Petersson (2010a) [40] } & C & 2 & 392 & DMFS & $3.00\left(^{\mathrm{a}}\right)$ & $2.70\left(^{\mathrm{a}}\right)$ & $1.50\left(^{\mathrm{a}}\right)$ & $0.50\left(^{\mathrm{a}}\right)$ & $0.20\left({ }^{\mathrm{a}}\right)$ \\
\hline & & & & DFS & $1.99(3.00)$ & $1.7(1.76)$ & $1.59(2.55)$ & $0.85(1.91)$ & $0.29(0.89)$ \\
\hline \multirow[t]{2}{*}{ Petersson $(2004)^{b}$ [34] } & C & 2 & 392 & DFS & $1.30\left(^{\mathrm{a}}\right)$ & $1.30\left(^{\mathrm{a}}\right)$ & $0.70\left(^{\mathrm{a}}\right)$ & $0.30\left(^{\mathrm{a}}\right)$ & $0.10\left({ }^{\mathrm{a}}\right)$ \\
\hline & A & 5 & 148 & DFS & $1.90\left(^{\mathrm{a}}\right)$ & $1.00\left(^{\mathrm{a}}\right)$ & $1.20\left(^{\mathrm{a}}\right)$ & $0.40\left(^{\mathrm{a}}\right)$ & $0\left(^{\mathrm{a}}\right)$ \\
\hline \multirow[t]{2}{*}{ Campus (2012) [35] } & C & 2 & 861 & DS & $1.20\left(^{\mathrm{a}}\right)$ & $1.20\left(^{\mathrm{a}}\right)$ & $0.10\left(^{\mathrm{a}}\right)$ & $0.20\left(^{\mathrm{a}}\right)$ & $\left.0.10{ }^{\mathrm{a}}\right)$ \\
\hline & & & & Cariogram & $0-20$ & $21-40$ & $41-60$ & $61-100$ & \\
\hline \multirow[t]{2}{*}{ Chang and Kim (2014) [42] } & C & 1.3 & 64 & DMFT & $2.97(5.2)$ & $1.28(1.5)$ & $1.36(2.2)$ & $0.44(0.7)$ & \\
\hline & & & & DMFS & $5.81(11.97)$ & $1.28(1.5)$ & $3.27(6.8)$ & $0.44(0.7)$ & \\
\hline \multirow[t]{2}{*}{ Petersson (2003) [1] } & A & 5 & & DMFS & $16.21(15.97)$ & $7.36(9.34)$ & $7.96(9.52)$ & $5.23(6.97)$ & \\
\hline & & & & Cariogram & $0-25$ & $26-50$ & $51-75$ & $76-100$ & \\
\hline \multirow[t]{2}{*}{ Twetman (2005) [33] } & C & 3 & 64 & DFS & $8(10.8)$ & $3.4(2.6)$ & $2.6(3.7)$ & $0(0)$ & \\
\hline & & & & Cariogram & $0-20$ & & $21-80$ & $81-100$ & \\
\hline \multirow[t]{3}{*}{ Zukanovic (2013) [41] } & C & 3 & 70 & DMFT & $1.80(1.79)$ & & $2.40(2.36)$ & $1.77(1.88)$ & \\
\hline & & & & DMFS & $5.00(7.07)$ & & $4.71(4.34)$ & $2.54(2.44)$ & \\
\hline & & & & Cariogram & $0-40$ & & & $41-100$ & \\
\hline \multirow[t]{2}{*}{ Holgerson (2009) [15] } & C & 5 & 125 & $\mathrm{dmfs} / \mathrm{DMFS}$ & $2.40(3.2)$ & & & $0.10(0.4)$ & \\
\hline & & & & Cambra & High & & Moderate & Low & \\
\hline Gao (2013) [36] & C & 1 & 485 & $\mathrm{dmft}$ & $1.24(1.58)$ & & $0.27(0.68)$ & $0.20(0.76)$ & \\
\hline \multirow[t]{2}{*}{ Chaffee (2015) [45] } & A & 1.5 & 4468 & DFT & $1.74\left(^{\mathrm{a}}\right)$ & & $1.16\left(^{\mathrm{a}}\right)$ & $1.01\left(^{\mathrm{a}}\right)$ & \\
\hline & & & & $C A T$ & High & & Moderate & Low & \\
\hline Gao (2013) [36] & C & 1 & 485 & $\mathrm{dmft}$ & $0.79(1.31)$ & & $0.08(0.28)$ & $0(0)$ & \\
\hline \multirow[t]{3}{*}{ Zukanovic (2013) [41] } & C & 3 & 70 & DMFT & $2.19(2.33)$ & & $2.60(1.82)$ & $2.38(1.92)$ & \\
\hline & & & & DMFS & $4.54(4.41)$ & & $3.80(5.81)$ & $3.13(2.53)$ & \\
\hline & & & & NUS-CRA & Very High & High & Moderate & Low & Very Low \\
\hline \multirow[t]{2}{*}{ Gao (2013) [36] } & C & 1 & 485 & $\mathrm{dmft}$ & $2.18(1.87)$ & $2.10(1.63)$ & $1.26(1.38)$ & $0.85(1.11)$ & $0.17(0.69)$ \\
\hline & & & & PreViser & High & & Moderate & Low & \\
\hline \multirow[t]{2}{*}{ Zukanovic (2013) [41] } & C & 3 & 70 & DMFT & $2.35(2.27)$ & & $1.92(2.18)$ & $2.18(2.32)$ & \\
\hline & & & & DMFS & $5.04(4.75)$ & & $3.08(2.87)$ & $2.82(3.19)$ & \\
\hline
\end{tabular}

A Adults, C Children

$\left({ }^{a}\right)$ indicates that Standard Deviation data were not described in the paper. The decimal places reported are those reported in each paper

Petersson, (2004) $)^{b}$ reports the increment for year of observation. Holgerson, (2009) and Petersson, (2010b) were excluded from the table since as no mean data for caries were present. Gao (2015) was excluded from the table as the data are the same as those reported for Gao, (2013)

In brief, the results of the present review show: all the included papers on children showed a statistically significant association between the risk levels and the actual caries status and/or the future increment. More than half of these papers, including the Cariogram model, were classified as being of good quality. The same positive association between the risk levels and the actual caries status and/or the future increment was reported in the included papers on adults. More than half of the papers were classified as being of good quality and all 
Table 4 Sensitivity and specificity of the Cariogram model in children and adults

\begin{tabular}{llllll}
\hline Authors (year) & Number of factors & Sample $n$ & Age at baseline (years) & $\begin{array}{l}\text { Sensibility \% } \\
\text { (95\%Confidence Interval) }\end{array}$ & $\begin{array}{l}\text { Specificity \% } \\
\text { (95\%Confidence Interval) }\end{array}$ \\
\hline Children & & & & & $78.5^{\mathrm{a}}$ \\
Gao (2013) [36] & Full & 485 & 3 & $66.4^{\mathrm{a}}$ & $79.5(99.2-54.7)$ \\
Campus (2012) [35] & 7 & 861 & $7-9$ & $52.0(18.6-94.6)$ & $65.8^{\mathrm{a}}$ \\
Gao (2010) [16] & Full & 1782 & $3-6$ & $70.5^{\mathrm{a}}$ & $88.0(71.0-104.0)$ \\
Holgerson ${ }^{\mathrm{b}}$ (2009) [15] & Full & $66^{\mathrm{b}}$ & 2 & $46.0(31.0-62.0)$ & $71.0^{\mathrm{a}}$ \\
Twetman (2005) [33] & Full & 64 & $8-16$ & $75.0^{\mathrm{a}}$ & $79.8(99.6-60.0)$ \\
Petersson (2002) [32] & Full & 392 & $10-11$ & $41.0(9.0-73.0)$ & \\
Adults & & & & $47.0(11.9-89.2)$ & $72.5(33.5-94.8)$ \\
Petersson (2015) [44] & Full & 1295 & 19 & &
\end{tabular}

Range not available

${ }^{\mathrm{b}}$ Control group only

except one used the Cariogram. Three of four papers comprising children and adults found a positive association between the risk levels and the actual caries status and/or the future increment.

\section{Discussion}

Determining the validity of different caries risk assessment models to fit the actual caries status, analyzing cross-sectional papers, and to predict new caries lesions in the near future, analyzing longitudinal papers, was the aim of this systematic review. The CRA models that were examined were the reasoning-based (CAT, CAMBRA and ADA model) and algorithm-driven (Cariogram, NUS-CRA and PreViser).

The findings described enable to draw some conclusions.

All papers involving children [15, 16, 21-25, 32-41] assessed a statistically significant association between the risk level measured by the CRA model and the actual caries status or the caries increment in a follow-up examination. Eleven papers [16, 21, 25, 32-36, 38-40] of seventeen were classified as being of good quality, and all of them used the Cariogram as sole model or in conjunction with other models. Sensibility and specificity of the Cariogram model were evaluated in six papers [15, $16,32,33,35,36]$ and data showed that the model is not accurate in predicting caries lesion development. Furthermore, the validity of the Cariogram to evaluate the caries risk might be flawed: four papers [32, 34, 39, 40] involved the same population.

Papers carried out on adult populations $[1,7,26-31$, 34, 42-45] showed a positive association between the CRA model and caries data. Eight papers $[1,7,28,30$, $31,42,44,45]$ of thirteen were classified as being of good quality and all except one [45] used the Cariogram model. Sensibility and specificity of the Cariogram model were reported in one paper [44]; data confirm the low accuracy of the model. Within the three papers [1820] involving both children and adults regarded as a single sample, two found a positive association between risk level and caries status and one [20] failed to find such an association. This last paper was evaluated as being of poor quality.

Different Cariogram models using from nine to seven factors were used. The excluded factors were salivary parameters, namely mutans streptococci, lactobacilli, salivary secretion rate and buffer capacity. Reduced Cariogram versions were statistically significant associated to caries data, in both cross-sectional and longitudinal papers [7, $21,29,30,35]$, except for one paper [20].

Only three papers, two of good quality (reporting data on the same sample) $[36,38]$ and one fair, compared different risk models [41]: the Full Cariogram, CAT, CAMBRA and NUS-CRA were compared in two and the Full Cariogram, PreViser and CAT in the third one. The results showed that different CRA models assessed the risk differently, but, due to the small amount of available data, it is not possible to draw clear conclusions about the most effective method for predicting caries lesions.

The main limitation of this review is that the included papers do not form a homogeneous group and original databases are not available making it impossible to perform a meta-analysis. Different study populations (adults or children), different versions of the same standardized CRA model (Cariogram from seven to nine parameters), different indices used to measure carious lesions ( $\mathrm{dmfs}$ / $\mathrm{t}, \mathrm{DMFS} / \mathrm{T}$, DFS/T, DS, ICDAS) make the comparison of papers questionable and hamper the synthesis of results. This limitation cannot be overcome until papers with a standardized study design, outcome measurements and reporting of data will be carried out.

At present, only the Cariogram was used in papers of good quality to assess its efficacy in predicting caries development, while, for the other standardized CRA models, the lack of papers does not make it possible to draw conclusions on their effectiveness. 


\section{Conclusions}

The evidence relating to the quality of existing CRA models in assessing and predicting caries lesions is limited; even if Cariogram was used in few studies of good quality carried out in children and adults, no sufficient evidence is available to affirm that the method is effective in caries assessment and prediction. The Full Cariogram and reduced versions, eight or seven factors, appear to produce similar results. Although other CRA models, such as CAT, CAMBRA, NUS-CRA and PreViser, might be effective in clinical settings, the scientific evidence to date is limited.

\section{Additional files}

Additional file 1: List of papers excluded in the first selection (XLSX 54 kb) Additional file 2: List of papers excluded in the second selection (XLSX $11 \mathrm{~kb}$ )

Additional file 3: Quality assessment (XLSX 13 kb)

\section{Abbreviations}

AAPD: American academy of pediatric dentistry; ADA: American dental association; CAMBRA: Caries management by risk assessment; CAT: Caries risk-assessment tool; CRA: Caries risk assessment; DMFT/S: Decayed missed filled tooth/surface; ICDAS: International caries detection and assessment system; NUS-CRA: National university of singapore- caries risk assessment; PRISMA: Preferred reporting items for systematic reviews and meta-analyses; $\mathrm{RCT}$ : Randomized clinical trial

\section{Acknowledgements}

The authors want to thank the authors of the included longitudinal papers who provided data for the analysis.

\section{Availability of data and materials}

All data generated or analysed during this study are included in this published article (and its additional files).

\section{Authors' contributions}

MGC: selected the papers, performed the papers validity assessment and drafting the manuscript; GB: performed the search and selected the papers; FC: realized tables and figure and contributed to write the manuscript; PL: performed the final revision of the paper; LS: designed the paper; GC: was consulted in case of discussion between the examiners of the validity assessment and contributed to write the paper. All authors read and approved the final version of the manuscript.

\section{Ethics approval and consent to participate}

Not applicable as this paper is a systematic review.

\section{Consent for publication}

Not applicable.

\section{Competing interests}

The authors declare that they have no competing interests. There are no financial completing interests as we have not received any grants. The authors alone are responsible for the content and writing of the paper.

\section{Publisher's Note}

Springer Nature remains neutral with regard to jurisdictional claims in published maps and institutional affiliations.

\section{Author details}

'Department of Biomedical, Surgical and Dental Sciences, University of Milan, Via Beldiletto 1, 20142 Milan, Italy. ${ }^{2}$ WHO Collaboration Centre for
Epidemiology and Community Dentistry, Via Beldiletto 1, 20142 Milan, Italy. ${ }^{3}$ Department of Surgery, Microsurgery and Medicine Sciences, School of Dentistry University of Sassari, Viale San Pietro, 43 Sassari, Italy. ${ }^{4}$ Department of Cariology, Institute of Odontology, The Sahlgrenska Academy, University of Gothenburg, Medicinaregatan 12 A-G, P.O. Box 450, 40530 Gothenburg, Sweden.

Received: 23 February 2018 Accepted: 5 July 2018

Published online: 16 July 2018

\section{References}

1. Petersson GH, Fure S, Bratthall D. Evaluation of a computer-based caries risk assessment program in an elderly group of individuals. Acta Odontol Scand. 2003;61:164-71.

2. Trottini M, Bossu M, Corridore D, lerardo G, Luzzi V, Saccucci M, Polimeni A. Assessing risk factors for dental caries: a statistical modeling approach. Caries Res. 2015;49:226-35.

3. Tellez M, Gomez J, Pretty I, Ellwood R, Ismail Al. Evidence on existing caries risk assessment systems: are they predictive of future caries? Community Dent Oral Epidemiol. 2013;41:67-78.

4. Senneby A, Mejare I, Sahlin NE, Svensäter G, Rohlin M. Diagnostic accuracy of different caries risk assessment methods. A systematic review. J Dent. 2015;43:1385-93.

5. Zhang Q, van Palenstein Helderman WH. Caries experience variables as indicators in caries risk assessment in 6-7-year-old Chinese children. J Dent. 2006:34:676-81.

6. Du Q, Yu M, Li Y, Du H, Gao W, Mei H, et al. Permanent caries experience is associated with primary caries experience: a 7-year longitudinal study in China. Community Dent Oral Epidemiol. 2016;45:43-8.

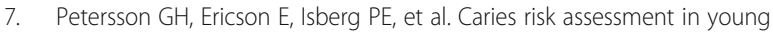
adults: a 3-year validation of clinical guidelines used in public dental service. Acta Odontol Scand. 2013;71:1645-50.

8. Arrica M, Carta G, Cocco F, et al. Does a social/behavioural gradient in dental health exist among adults? A cross-sectional study. J Int Med Res. 2017:45:451-61.

9. American Dental Association. Caries diagnosis and risk assessment. A review of preventive strategies and management. J Am Dent Assoc. $1995 ; 126: 1 s-24 s$.

10. Mejare I, Axelsson S, Dahlen G, Espelid I, Norlund A, Tranæus S, et al. Caries risk assessment. A systematic review. Acta Odontol Scand. 2014;72:81-91.

11. Aleksejūnienè J, Holst D, Brukienè V. Dental caries risk studies revisited: causal approaches needed for future inquiries. Int J Environ Res Public Health. 2009;6:2992-3009.

12. Doméjean S, Banerjee A, Featherstone JDB. Caries risk/susceptibility assessment: its value in minimum intervention oral healthcare. Br Dent J. 2017;223:191-7.

13. Senneby A, Mejàre I, Sahlin NE, Svensäter G, Rohlin M. Diagnostic accuracy of different caries risk assessment methods. A systematic review. J Dent. 2015;43:1385-93.

14. Bratthall D, Petersson GH. Cariogram-a multifactorial risk assessment model for a multifactorial disease. Community Dent Oral Epidemiol. 2005;33:256-64.

15. Holgerson PL, Twetman S, Stecksen-Blicks C. Validation of an age-modified caries risk assessment program (Cariogram) in preschool children. Acta Odontol Scand. 2009;67:106-12.

16. Gao XL, Hsu CY, Xu Y, Hwarng HB, Loh T, Koh D. Building caries risk assessment models for children. J Dent Res. 2010;89:637-43.

17. Quality Assessment Tool for Observational Cohort and Cross-Sectional Studies Available from: https://www.nhlbi.nih.gov/health-pro/guidelines/indevelop/cardiovascular-risk-reduction/tools/cohort

18. Almosa NA, Al-Mulla AH, Birkhed D. Caries risk profile using the Cariogram in governmental and private orthodontic patients at de-bonding. Angle Orthod. 2012;82:267-74.

19. Al Mulla AH, Kharsa SA, Kjellberg H, Birkhed D. Caries risk profiles in orthodontic patients at follow-up using Cariogram. Angle Orthod. 2009; 79:323-30.

20. Giacaman RA, Miranda Reyes P, Bravo Leon V. Caries risk assessment in Chilean adolescents and adults and its association with caries experience. Braz Oral Res. 2013;27:7-13.

21. Sundell AL, Ullbro C, Marcusson A, Twetman S. Comparing caries risk profiles between 5- and 10-year-old children with cleft lip and/or palate and non-cleft controls. BMC Oral Health. 2015;15:85. 
22. Cabral RN, Hilgert LA, Faber J, et al. Caries risk assessment in schoolchildren-a form based on Cariogram software. J Appl Oral Sci. 2014;22:397-402.

23. Hebbal M, Ankola A, Metgud S. Caries risk profile of 12 year old school children in an Indian city using Cariogram. Med Oral Patol Oral Cir Bucal. 2012;17:e1054-61.

24. Kavvadia K, Agouropoulos A, Gizani S, Papagiannouli L, Twetman S. Caries risk profiles in 2- to 6-year-old Greek children using the Cariogram. Eur J Dent. 2012;6:415-21.

25. Campus G, Cagetti MG, Sacco G, Benedetti G, Strohmenger L, Lingström P. Caries risk profiles in Sardinian schoolchildren using Cariogram. Acta Odontol Scand. 2009:67:146-52.

26. Ruiz Miravet A, Montiel Company JM, Almerich Silla JM. Evaluation of caries risk in a young adult population. Med Oral Patol Oral Cir Bucal. 2007;12:E412-8.

27. Peker I, Mangal T, Erten H, Gulcin A, Emre A, Gulcin A. Evaluation of caries risk in a young adult population using a computer-based risk assessment model (Cariogram). J Dent Sci. 2012;7:99-104.

28. Sonbul $\mathrm{H}, \mathrm{Al}$-Otaibi M, Birkhed D. Risk profile of adults with several dental restorations using the Cariogram model. Acta Odontol Scand. 2008;66:351-7.

29. Lee JH, Son HH, Kim HY, Chang J. Caries risk profiles of Korean dental patients using simplified Cariogram models. Acta Odontol Scand. 2013;71:899-905.

30. Chang J, Lee JH, Son HH, Kim HY. Caries risk profile of Korean dental patients with severe intellectual disabilities. Spec Care Dentist. 2014;34:201-7.

31. Carta G, Cagetti MG, Cocco F, Sale S, Lingström P, Campus G. Caries-risk profiles in Italian adults using computer caries assessment system and ICDAS. Braz Oral Res. 2015;29:S1806-83242015000100306.

32. Petersson GH, Twetman S, Bratthall D. Evaluation of a computer program for caries risk assessment in schoolchildren. Caries Res. 2002;36:327-40.

33. Twetman S, Petersson GH, Bratthall D. Caries risk assessment as a predictor of metabolic control in young type 1 diabetics. Diabet Med. 2005;22:312-5.

34. Petersson GH, Fure S, Twetman S, Bratthall D. Comparing caries risk factors and risk profiles between children and elderly. Swed Dent J. 2004;28:119-28.

35. Campus G, Cagetti MG, Sale S, Carta G, Lingström P. Cariogram validity in schoolchildren: a two-year follow-up study. Caries Res. 2012;46:16-22.

36. Gao X, Di Wu I, Lo EC, Chu CH, Hsu CY, Wong MC. Validity of caries risk assessment programmes in preschool children. J Dent. 2013:41:787-95.

37. Kemparaj U, Chavan S, Shetty NL. Caries risk assessment among school children in davangere city using cariogram. Int J Prev Med. 2014;5:664-71.

38. Gao XL, Lo ECM, Chu CH, Hsu SC. Caries risk assessment programmes for Hong Kong children. Hong Kong Med J. 2015;21:S42-S6.

39. Petersson GH, Isberg PE, Twetman S. Caries risk assessment in school children using a reduced Cariogram model without saliva tests. BMC Oral Health. 2010;10:5.

40. Petersson GH, Isberg PE, Twetman S. Caries risk profiles in schoolchildren over 2 years assessed by Cariogram. Int J Paediatr Dent. 2010;20:341-6.

41. Zukanovic A. Caries risk assessment models in caries prediction. Acta Med Acad. 2013:42:198-208.

42. Chang J, Kim HY. Does caries risk assessment predict the incidence of caries for special needs patients requiring general anesthesia? Acta Odontol Scand. 2014;72:721-8.

43. Celik EU, Gokay N, Ates M. Efficiency of caries risk assessment in young adults using Cariogram. Eur J Dent. 2012;6:270-9.

44. Petersson GH, Twetman S. Caries risk assessment in young adults: a 3 year validation of the Cariogram model. BMC oral health. 2015;15:17.

45. Chaffee BW, Cheng J, Featherstone JD. Baseline caries risk assessment as a predictor of caries incidence. J Dent. 2015;43:518-24.

\section{Ready to submit your research? Choose BMC and benefit from:}

- fast, convenient online submission

- thorough peer review by experienced researchers in your field

- rapid publication on acceptance

- support for research data, including large and complex data types

- gold Open Access which fosters wider collaboration and increased citations

- maximum visibility for your research: over $100 \mathrm{M}$ website views per year

At BMC, research is always in progress.

Learn more biomedcentral.com/submissions 